Received: 31/05/2018

Revision: 26/07/2018

Accepted: 30/07/2018

OnlineFirst: 04/10/2018

\title{
The Effectiveness of Research Based Learning in Improving Students' Achievement in Solving Two-Dimensional Arithmetic Sequence Problems
}

\section{Suntusia}

S.Pd, Graduate Student of Mathematics Education, Faculty of Teacher Training and Education, University of Jember, Jember, Indonesia, suntusiahafiza@gmail.com

\section{Dafik}

Prof, Dean, Faculty of Teacher Training and Education, University of Jember, Jember, Indonesia,d.dafik@gmail.com

\section{Hobri}

Dr., Head, Departemant of Post-Graduate Mathematics Education, Faculty of Teacher Training and Education, University of Jember, Indonesia, hobri1973@gmail.com

$$
\mid
$$

The present study aims to investigate the effectiveness of Research Based Learning (RBL) in improving students' learning achievement in solving two dimensional arithmetic sequence problems. The study applied triangulation method including qualitative and quantitative methods. The research subjects were 4thsemester students of higher education. The quantitative method was applied to analyse the learning achievement test, while the qualitative one was applied in the form of observation and interview. The collected data were analysed by using inferential statistics t-test. The result of t-test indicates that the sig (2-tailed) of independent sample t-test of pre-test is 0.853 ( $p>0,05)$, thus it is not significant. It implies the two classes are homogeneous in term of student achievement test. The data analysis of independent sample t-test of post-test, the sig (2-tailed) is 0.00 $(\mathrm{p}=<0,05)$, thus it is significant. It implies that the student achievement tests of two classes are different after the implementation of RBL. It shows that the students' achievement result of experimental class is better than the control class. The implementation of $\mathrm{RBL}$ is proven effective in improving students learning achievement in solving two-dimensional arithmetic problems.

Keywords: Research Based Learning, students' achievement test, two-dimensional arithmetic sequence, teaching, learning

\section{INTRODUCTION}

Education continues to change especially in the current industry 4.0. Likewise, the

Citation: Suntusia, Dafik, \& Hobri. (2019). The Effectiveness of Research Based Learning in Improving Students' Achievement in Solving Two-Dimensional Arithmetic Sequence Problems. International Journal of Instruction, 12(1), 17-32. https://doi.org/10.29333/iji.2019.1212a 
models of Mathematics have to change so that Mathematics education can be relevan with the challenges and opportunities in real life. These days, college graduates are required to master the $4 \mathrm{C}$ ability (communication, collaboration, critical thinking, and creativity), which allows them to succeed in the new industrial era.

The ability of 4C is able to develop students' thinking process systematically in education. Educational targets can be achieved with several approaches, one of which is through Research Based Learning (RBL). Education strategy is very important to change students' mind-set and reveal the unknown to improve learning aspects, especially alluding to cognitive, affective, and psychomotor. As an attempt to improve academic achievement, we introduce a Research Based Learning (RBL). RBL is a concept which refers to learning and teaching strategies i.e. linking research and teaching (Sota, 2017:1360). Research Based Learning is considered to be able to improve academic achievement, promote learning process, and encourage students to build knowledge (Blackmore \& Fraser, 2007). This ability is very important for the $21^{\text {st }}$ century education (Brew, 2010).

In this study, we applied Research Based Learning in accordance with the vision of educational development, while the purpose of this study is to improve students' achievement as well as to improve the students' problem solving skills. In the Research Based Learning, students work individually or in groups to solve two-dimensional arithmetic sequence problems to find new patterns of two-dimensional arithmetic sequence, continued by finding the general formula of the obtained pattern. Students are encouraged to find a unique pattern which is different with other students. They then should generalize and develop the formula of the pattern. Their process of finding the pattern, generalisation and finding formula of the pattern become a main activity of students' raising the data source of the research apart from the data collected from students achievement test.

According to Dafik (2015), RBL is a learning method which involves contextual learning, authentic learning, problem-solving, cooperative learning, hands-on \& minds on learning, and inquiry discovery approach. The RBL implementation aims to encourage the development of higher-order thinking skills on the part of both lecturers and students. Students are not only provided with information and Science, but also encouraged to attain higher-order thinking skill, creating or communicating. Dafik (2016) explains that Research Based Learning has advantages for learners, encompassing increased motivation to learn, improved ability to do important work, and improved problem solving skills, especially when dealing with complex problems. What is more, RBL encourages students to be more active and thus skilled in solving complex problems, makes learning fun, and improves cooperation, interactivity and mutual collaboration. Furthermore, it offers the benefits in developing and practicing communication skills, improving learners' skills in managing resources, providing experience in organizing projects, assisting in the allocation of time and resources, other sources to accomplish the task, and providing a learning experience that involves learners. Offering the aforementioned benefits, RBL empowers students to master complex skills required in the evolving world. This is because it involves learners to 
gather information, excel at their own rate, and then implement learnt concept in realworld context. At this stage, students are more likely to be involved in learning (studentcentred learning). Therefore, lecturers play more role as facilitator during discussion, when possible to help students dealing with any problems. The main characteristic of the implementation Research Based Learning is the existence of Research Group (RG). RG is a group of researchers who work on teaching, research, community services activities, and supervising on specific research of interest to solve a fundamental problem from a simple to complex problem, from new theory to new application. Once we have RG, we implement the Research Based Learning by using the following phase, see Figure 1.

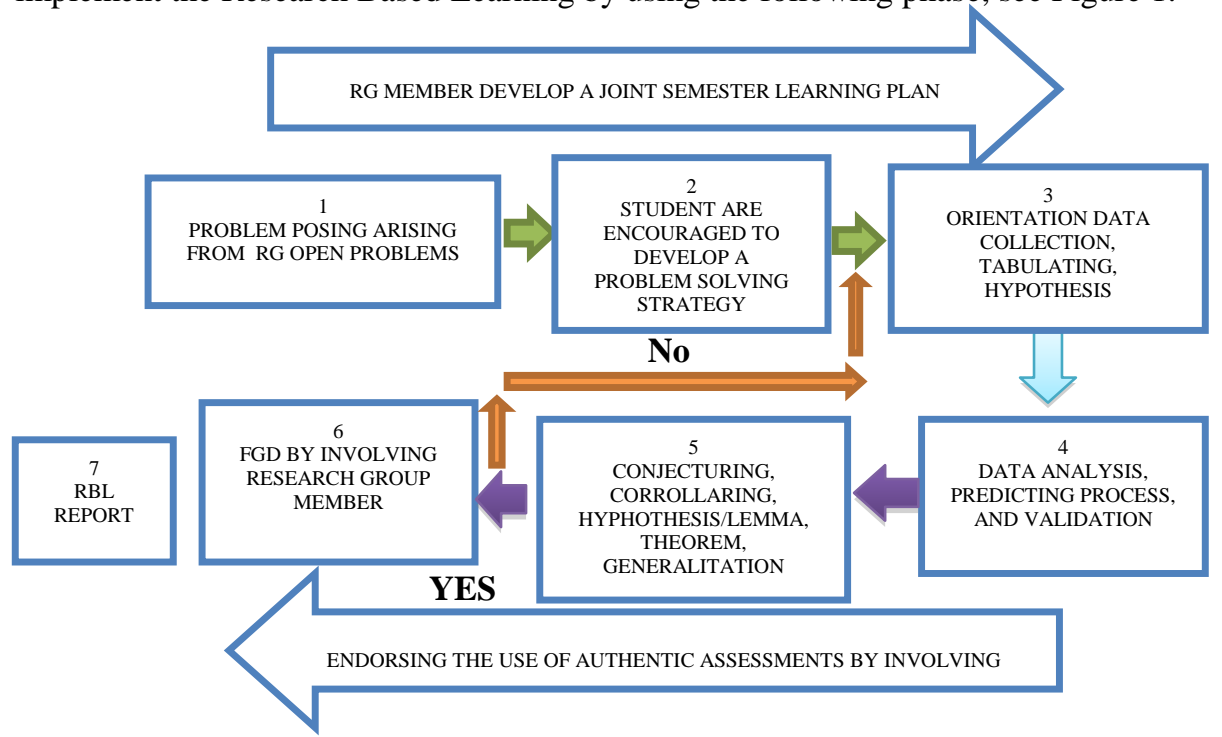

Figure 1

The stages of implementation of Research Based Learning (Dafik 2018)

Based on Arifin's research model (2010), there are three main steps in Research Based Learning, namely exposure stage, experience stage, and capstone stage. At the exposure stage, students deal with collecting information based on inquiry and searching literature relevant to topic under investigation (focused topic). Second, at the experience stage, the students work on identifying and formulating problems based on literature studies and experimental experience. At the last stage, capstone stage, they experiment on plans or ideas in providing solutions, algorithm, measurement, or computation.

Combining the two RBL models, proposed by Dafik and Arifin, the researchers mixed the two and produced a different procedure or syntax of RBL especially dealing with solving two-dimensional arithmetic sequence problems. First, the students are asked to understand the proposed problems of two-dimensional arithmetic sequence problems, student are encouraged to develop a problem solving strategy to the given problem, setudents gather information and locate some relevant literatures. Second, the students are encouraged to identify partial solution and start to generalize locally based on the 
pattern recognition. Third, the students conduct an analysis on the global pattern to generate two-dimensional arithmetic sequence problem. Fourth, the students complete the whole process generalization to produce an algorithm of desired two-dimensional arithmetic sequence problem. Fifth, the students write an RBL report supervised by the research group members.

The purpose of this research was to investigate the effectiveness of Research-Based Learning compared with conventional model in solving two-dimensional arithmetic sequence problem. By two-dimensional arithmetic sequence problem, we mean the problem in the following. This concept was introduced in (Baca, et. Al, 2017) and (Dafik, 2018), with the name of an integer set of partition.

Definition 1. Let $n, m, d$ and $k$ be positive integers. We concider the partition $P_{m, d}^{n}(i, j)$

of the set $\{1,2, \ldots, m n\}$ into $n$ columns, $n \geq 2, m$-rows such that the difference between the sum of the number in the $(i+1)$ th $m$-rows and the sum of the numbers in the $i$ th $m$-rows is always equal to the constant $d$, where $i=1,2, \ldots, n-1$. Thus these sums form an arithmetic sequence with the difference d. By the symbol $P_{m, d}^{n}(i, j)$ we denote $i$ th $m$-rows in the partition with the difference $d$, where $i=1,2, \ldots, n$. Let $\sum P_{m, d}^{n}(i, j)$ be the sume of the numbers in $P_{m, d}^{n}(i, j)$, thus $d=\sum P_{m, d}^{n}(i+1, j)-\sum P_{m, d}^{n}(i, j)$.

In this study, the students were asked to find new patterns of two-dimensional arithmetic sequence satisfying the above definition and following the syntax given in the above steps of RBL. While other classes were taught by using conventional learning model and asked to do the same thing, i.e. finding new patterns of two-dimensional arithmetic sequence. The basic concept of arithmetic sequence is actually of the form $u_{1}, u_{2}, u_{3}, \ldots$, $u_{n}$ with $d=u_{n}-u_{n-1}=u_{n-1}-u_{n-2}$, where $d$ is a difference, but in this study we analyse the arithmetic sequence of two dimensions in term of $n$ column and $m$ rows, which considered to be more complex problems.

\section{METHOD}

We applied a triangulation method combining qualitative and quantitative methods. Quantitative method aimed to analyse the data taken from students achievement test after the implementation of RBL method, while qualitative method aimed to analyse the data taken from the observations and interviews to selected students. The study investigated two variables, comprising the implementation of RBL as the independent variable and the students' achievement test of solving two-dimensional arithmetic sequence problem as the dependent variable. To know deeply of the effectiveness of the implementation of RBL, we continued the study by distributing observation to all 
students of experimental class and selecting several students to be interviewed about their understanding process of finding a new pattern of two-dimensional arithmetic sequence as well as generalising the new pattern.

The experimental design of this research was setup two group of classes, namely experiment class and control class, which were chosen by purposive random sampling and examined by pre-test and post-test by using the following design.

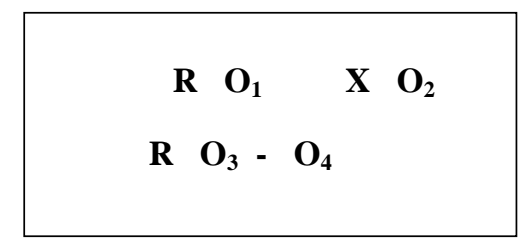

$\mathrm{R}=$ both experimental and control class were chosen randomly

$\mathrm{O}_{1} \& \mathrm{O}_{3} \quad=$ both groups were examined using pre-test in order to find out their competence, which was expected to be at the same level.

$\mathrm{O}_{2} \quad=$ the post-test result of experimental class

$\mathrm{O}_{4} \quad=$ the post-test result of control class (Sugiono, 2017)

In this design, there were two groups chosen randomly (R). The first group was put under a treatment $(\mathrm{X})$, while the other received no treatment. The group receiving the treatment was named experimental class, while the other one was as a control class.

The effect of treatment is represented as $\left(\mathrm{O}_{2}: \mathrm{O}_{4}\right)$, in the present study. The effect of treatment was analysed using t-test, as proposed by Sugiono (2017). Figure 2 shows a triangulation model in which qualitative data is triangulated with quantitative data to determine the effect of Research Based Learning in improving students' achievement in solving two-dimensional arithmetic sequence problems, Sugiono ( 2017). 


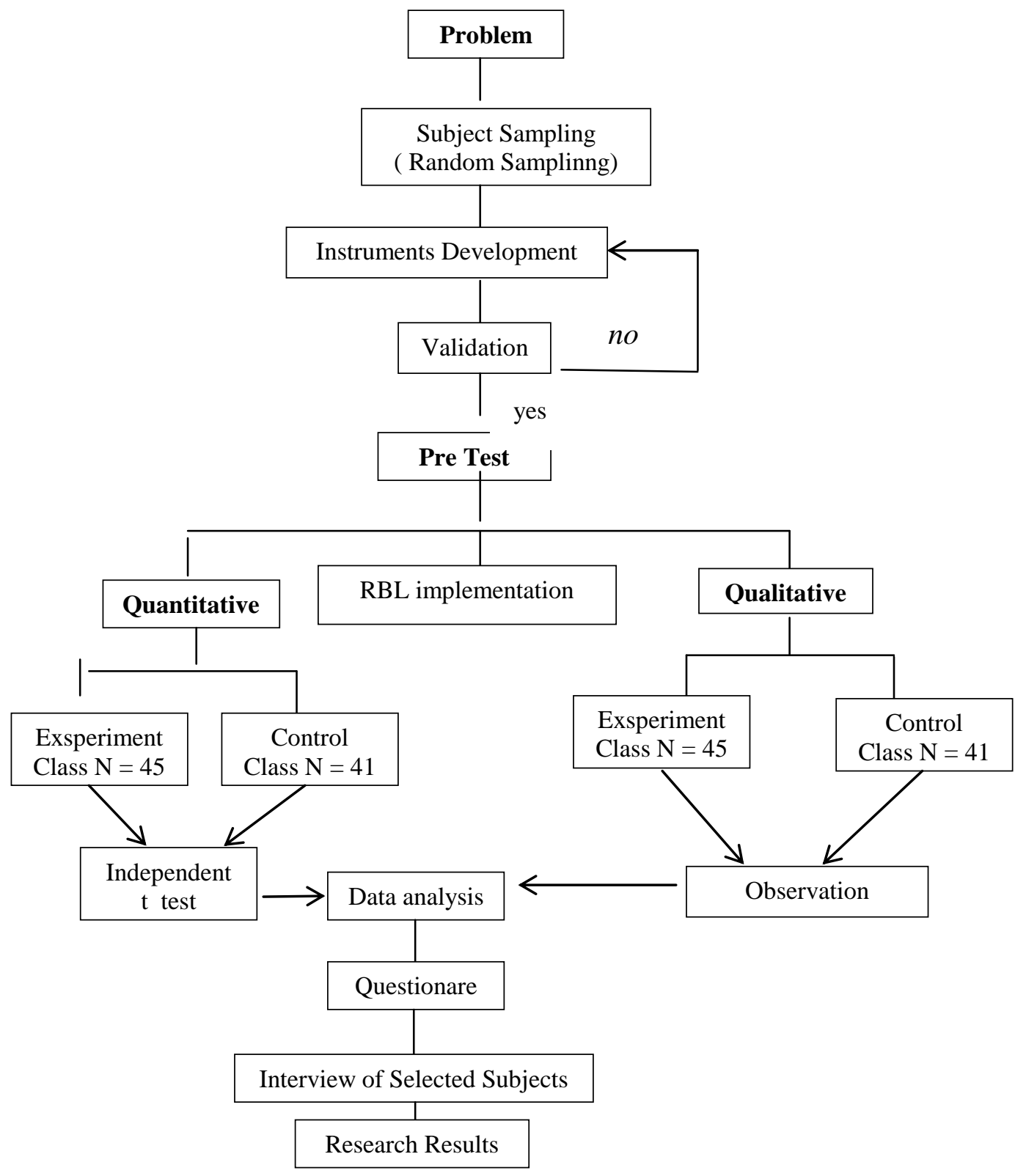

Figure 2

The model of triangulation method 


\section{Population}

The population of this study were $4^{\text {th }}$-semester students of the department of mathematics education of the University of Jember. The study applied cluster sampling by selecting two classes randomly, resulting in one experimental class of 45 students taught using RBL model. This class comprised of 12 males and 33 females. Another class, the control class, was taught using the conventional learning model. The latter consisted 8 men and 33 women. Data collection was conducted from February to May 2018. The research instruments included test, questionare and observation sheet. To collect data on learning achievement, the authors used a set of test to find new patterns in which the students should be able to generalize into general bijection. The observation sheet was used to check the students understanding and activity during solving the problems, and the questionare was aimed to know the students perception of RBL implementation.

\section{Instruments}

The instruments included test, observation, interviews, and observations. The researcher only distributed the observation to all subjects in the experimental class with 10 items done by 10 observers. The observation used a Likert scale encompassing Very Active (Score 5), Active (Score 4), Hesitate (score 3), Inactive (score 2), Very Inactive (score 1). The test, observation, interviews were validated by an expert of mathematics education.

\section{Task}

In this research, the researchers gave the following task to the subjects of both experiment class and control class. To measure the students' ability, appropriate instrument complying with the indicators was developed which were different from the previous researchers. The test distributed to all subjects of both experiment class and control class. The columns are represented by $j$, while the rows are are represented by $i$.

The difference between the sum of the number in the $(i+1)$ th $m$-rows and the sum of the numbers in the $i$ th $m$-rows is always equal to $d$. The following table are the illustration of the task.

$n, m$ are the number of column and rows $(\mathrm{n}=3, m=2)$

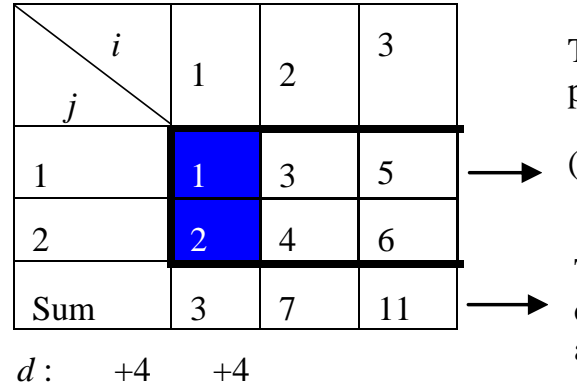

The figures are placed vertically

(first pattern)

The sum of each column forms an arithmetic sequence

Figure 3

Example of the partition set of $P_{2,4}^{3}(i, j)$ 
The same colour indicates the same pattern to producing a pattern of two-dimensional arithmetic sequence. In this case, $n=3$, and $m=2$, and the difference of the sum series form an arithmetic sequence of difference $d=2$. The purpose of the task is that students can create a new two-dimensional arithmetic sequence pattern which is not the same with other individual student under the implementation of RBL.

\section{Data Collection and Analysis}

Experimental class and control class took both pre-test and post-test. The quantitative analyse was applied by t-test. The qualitative data was carried out by using interviews and observations instruments and analyse based on the ordinal data.

Descriptive and inferential statistics were applied to analyse quantitative and qualitative data. Information derived from the data, i.e. frequency, mean, and standard deviation, was used to describe statistical data. Moreover, the inferential statistic was pertinent to the RBL impact t-test sample between the experimental class and the control class (Hilton et al, 2004). Independent samples were used to compare between the mean scores of the two groups, the significance of which was confirmed by difference at 0.05 level.

\section{FINDINGS}

Referring to the research results, the findings concerned with the effectiveness of RBLbased learning of independent sample $t$-test using $t$-test analysis were obtained from the pre-test and post test scores on the average of the experimental class and control class. The data normality test was examined prior to further analysis. The total number of respondents was 86 students. This evinced that the pre-test results of both classes was significantly different, as seen in Table 1 and Table 2.

Table 1

The table displays pre-test results and mean values between the control class and the experimental class.

\begin{tabular}{lllll}
\hline Group & N & Mean & $\begin{array}{l}\text { Std. } \\
\text { Deviation }\end{array}$ & $\begin{array}{l}\text { Std. Error } \\
\text { Mean }\end{array}$ \\
\hline The Pre-test score of Control class & 41 & 65,4878 & 13,09985 & 2,04585 \\
The Pre-test score of Experimental class & 45 & 66,000 & 12,45902 & 1,85728 \\
\hline
\end{tabular}

Distribution of pre-test results reaches 0.05 and post skewness test is marked at 0.00 . The average grade in the control class reaches $65,4878(\mathrm{SD}=13,09985)$, while that of experimental class is marked by an average score of $66,000(\mathrm{SD}=12,45902)$. The difference in the pre-test scores between both groups is [ $t(86)=0,611, p>0,05]$, which is found insignificant. 
Table 2

The data below presents the comparison of pre-test score of experiment class and control class score using independent sample t-test

\begin{tabular}{|c|c|c|c|c|c|c|c|c|c|c|}
\hline & & \multicolumn{2}{|c|}{$\begin{array}{c}\text { Levene's Test } \\
\text { For Equality of } \\
\text { Variances } \\
\end{array}$} & \multicolumn{7}{|c|}{ t-test for Equality of Means } \\
\hline & & \multirow[t]{2}{*}{$\mathrm{F}$} & \multirow[t]{2}{*}{ Sig. } & \multirow[t]{2}{*}{$\mathrm{t}$} & \multirow[t]{2}{*}{ df } & \multirow[t]{2}{*}{$\begin{array}{l}\text { Sig. } \\
(2- \\
\text { tailed })\end{array}$} & \multirow[t]{2}{*}{$\begin{array}{c}\text { Mean } \\
\text { Difference }\end{array}$} & \multirow[t]{2}{*}{$\begin{array}{l}\text { Std. Error } \\
\text { Difference }\end{array}$} & \multicolumn{2}{|c|}{$\begin{array}{l}\text { 95\% Confidence } \\
\text { Interval of the } \\
\text { Difference }\end{array}$} \\
\hline & & & & & & & & & Lower & Upper \\
\hline \multirow[t]{2}{*}{$\begin{array}{l}\text { nilai_ } \\
\text { pre_- } \\
\text { test }\end{array}$} & $\begin{array}{l}\text { Equal } \\
\text { variances } \\
\text { assumed }\end{array}$ & 0,261 & ,611 & -.186 & 84 &, 853 &,- 51220 & 2,75664 & $-5,9941$ & 4,96969 \\
\hline & $\begin{array}{l}\text { Equal } \\
\text { variances } \\
\text { not } \\
\text { assumed }\end{array}$ & & & -.185 & 82,3 &, 853 &,- 51220 & 2,76315 & -6.0087 & 4,98431 \\
\hline
\end{tabular}

Table 2 also shows that the result of t-test indicates the sig (2-tailed) of independent sample t-test of pre-test is 0.853 ( $p>0,05)$, thus it is not significant. It implies the two classes are homogeneous in term of student achievement test.

Table 3

The post-test results and mean between control class and experimental class

\begin{tabular}{lllll}
\hline Group & N & Mean & Std. Deviation & Std. Error Mean \\
\hline The Pre-test score of Control class & 41 & 75,5610 & 5,73606 &, 89582 \\
The Pre-test score of Experimental class & 45 & 82,4444 & 4,04270 &, 60265 \\
\hline
\end{tabular}

Table 3 presents the post-test results of control class, marked at 75,5610 (SD = 5,73606), while the experimental class gained 82,4444 ( $\mathrm{SD}=4,04270)$. Table 4 shows that there is significant difference between the two classes as indicated by $[\mathrm{t}(\mathrm{86})=-$ $6,477, \mathrm{p}<0.05]$.

Table 4

The comparison of post-test scores and average scores of both classes based on the independent sample t-test.

\begin{tabular}{|c|c|c|c|c|c|c|c|c|c|c|}
\hline & & \multicolumn{2}{|c|}{$\begin{array}{c}\text { Levene's Test } \\
\text { For Equality } \\
\text { of Variances }\end{array}$} & \multicolumn{7}{|c|}{ t-test for Equality of Means } \\
\hline & & \multirow[t]{2}{*}{$\mathrm{F}$} & \multirow[t]{2}{*}{ Sig. } & \multirow[t]{2}{*}{$\mathrm{t}$} & \multirow[t]{2}{*}{$\mathrm{df}$} & \multirow[t]{2}{*}{$\begin{array}{l}\text { Sig. } \\
(2- \\
\text { tailed })\end{array}$} & \multirow[t]{2}{*}{$\begin{array}{c}\text { Mean } \\
\text { Difference }\end{array}$} & \multirow[t]{2}{*}{$\begin{array}{l}\text { Std. Error } \\
\text { Difference }\end{array}$} & \multicolumn{2}{|c|}{$\begin{array}{l}\text { 95\% Confidence } \\
\text { Interval of the } \\
\text { Difference }\end{array}$} \\
\hline & & & & & & & & & Lower & Upper \\
\hline \multirow[t]{2}{*}{ nilai_post_test } & $\begin{array}{l}\text { Equal } \\
\text { variances } \\
\text { assumed }\end{array}$ & 7,837 & ,006 & $-6,477$ & 84 &, 000 & $-6,88$ & 1,062 & $-8,99$ & $\overline{4} \overline{77}$ \\
\hline & $\begin{array}{l}\text { Equal } \\
\text { variances } \\
\text { not } \\
\text { assumed }\end{array}$ & & & $\begin{array}{c}- \\
6,376\end{array}$ & 77,15 &, 000 & $-6,88$ & 1,079 & $-9,036$ & $-4,73$ \\
\hline
\end{tabular}

Furthermore, Table 4 also shows that the result of t-test indicates the sig (2-tailed) of independent sample t-test of post-test is $0.00(\mathrm{p}=<0,05)$, thus it is significant. It implies 
that the two classes are differences in term of student achievement test after the implementation of RBL.

According to this result we can conclude that there is significant impact of Research Based Learning implementation to the students' achievement in solving twodimensional arithmetic sequence problem.

To convince our result we distributed observation to all subjects of experimental class, items done by 10 observers, and it used a likert scale encompassing Very Active (Score 5), Active (Score 4), Hesitate (score 3), Inactive (score 2), Very Inactive (score 1). The observation results can be shown in the following chart.

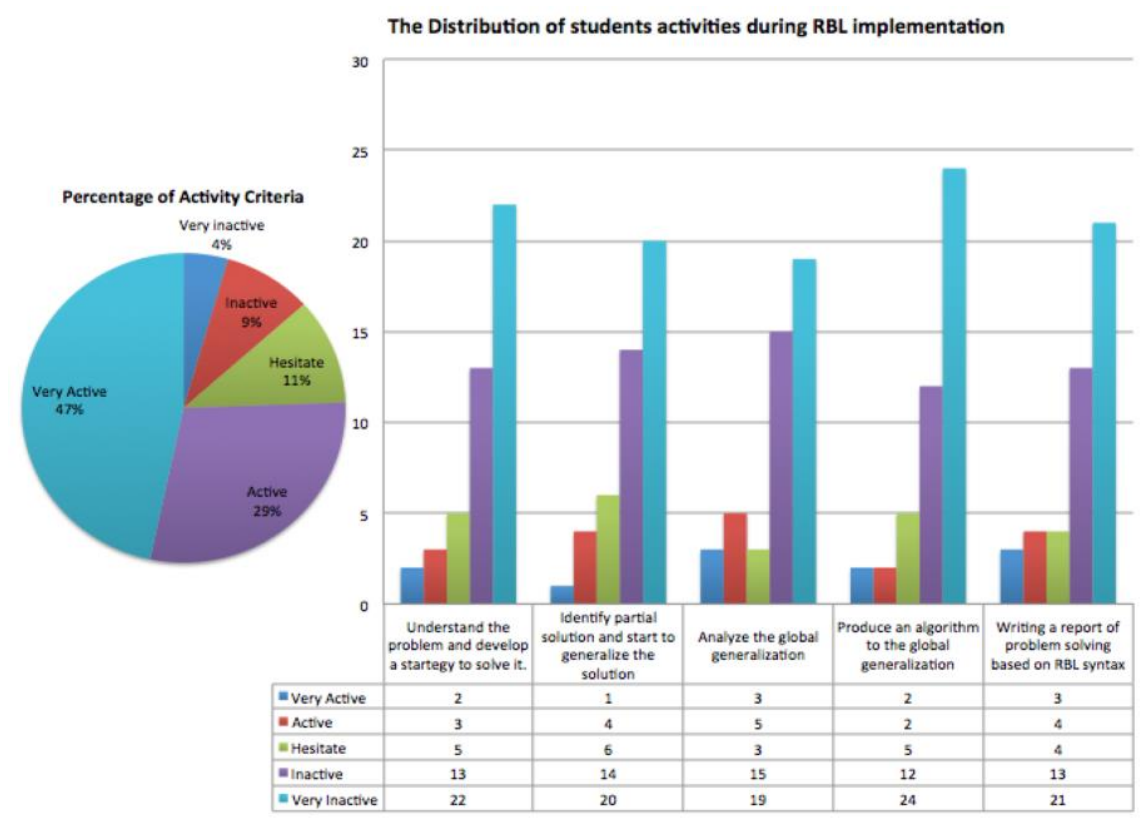

Figure 4

The observation results distribution of all subjects in the experimental class

Based on figure 4 , the student involved in the observation are 45 students. It is found that the highest score of observation criteria reaches $47 \%$ of research subjects which indicates that, during RBL implementation, students are strongly active to engage with the problem solving, and $29 \%$ of students reach the active level, and the rest of $26 \%$ are in the hesitate, inactive and very inactive levels. It can be concluded that RBL can work well in the learning process on solving two-dimensional arithmetic sequence problems.

From observation process of the students test results, it shows that students become competent in manipulating various concepts of two-dimensional arithmetic sequence problems. This competence proved that they were able to naturally use their competence to create new patterns which are different from the others. However, under the 
interviews process, it was found that many competent students had difficulty in generalising the patterns for forming a two-dimensional arithmetic sequence. By implementing the RBL in the experimental class, the research showed that students were supervised to find a new way to solve the two-dimensional arithmetic sequence problem. In the following illustration show how students create the new pattern of twodimensional arithmetic sequence problem and generalise the pattern.

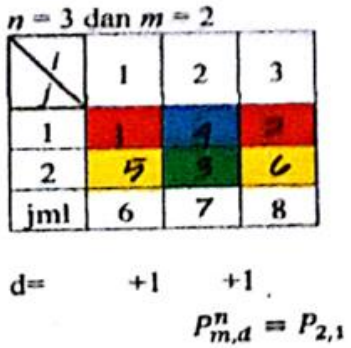

Figure 5

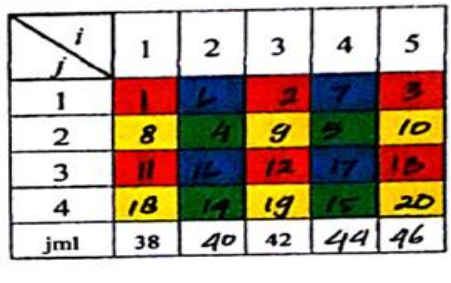

$\mathrm{d}=+2+2+2+2$

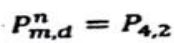

One of the student's work with the partition set pattern of $P_{m, m / 2}^{n}(i, j)$

Efforts made by the students, see Figure 5, to solve the problems employ the principle of addition and subtraction. They were considered able to expand the pattern by filling the red areas, encompassing number $1,2,3,11,12$, and 13, while the blue areas included $6,7,16$, and 17 . The yellow areas were marked by $8,9,10,18,19$, and 20 , and the green areas comprised of $4,5,14,15$. When the numbers in a column were summed, then they proceeded to the next column until they created the sequence involving 38, 40, 42, 44, and 46 to produce the same difference denoted by $d=2$.

The student's presumption concerning the expansion was to increase the number of rows and the number of the columns from figure one for the first case, which included 2 rows and 3 columns. The second case called for the expansion resulting in 4 rows and 5 columns, performed using the same colouring. Based on the RBL syntax, combining the first step in the completion of Figure 5, the information was collected using the basic principle of calculation. The second step was to identify the problem by grouping the red areas filled with sequence numbers $1,2,3,11,12$, and 13, while the blue areas included 6.7, 16, and 17. The yellow areas corresponded to 8, 9, 10, 18, 19, and 20, while the green areas were marked by $4,5,14$, and 15 . Upon data analysis the two tables in column were summed, and then they were preceded to next column, which forms an arithmetic sequence $38,40,42,44$, and 46 . The fourth step was the generalization, performed after all table in column were summed up to form a sequence corresponding to the same difference. Afterward, they added the number of rows and the number of columns on the first table for the first case, involving 2 rows and 3 columns. The second case was expanded into 4 rows and 5 columns, performed using the same colouring technique.

Furthermore, upon the other observation, the other pattern found by students can be described in the following. 

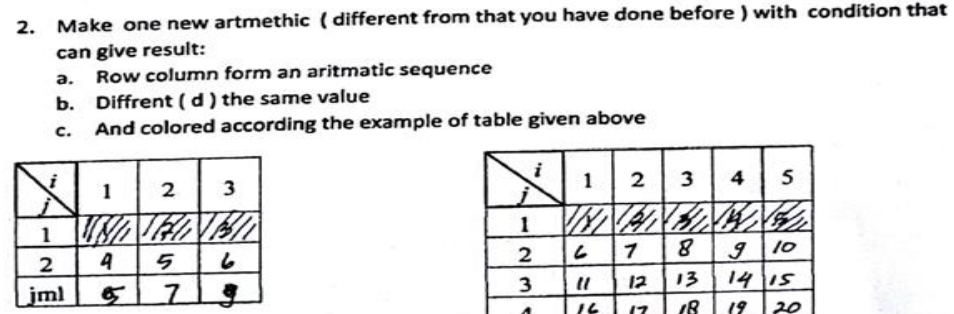

Figure 6

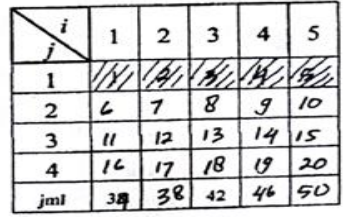

One of the student's work with the partition set pattern of $P_{m, m}^{n}(i, j)$

The problem-solving strategy on the aforementioned question was useful. The two dimensional pattern of arithmetic sequence indicates that a problem could be solved using the same strategy but in different context. However, in the present study, the researchers revealed that the students, with strong mathematics background and comprehensive experience in calculation, applied a slightly different strategy to identify the new pattern which is different to what had been done. By blocking the areas, they could generate a sequence involving 1,2, and 3 in one line. The sequence was coloured to indicate that the figures represented a sequence. Also, the students were able to expand the pattern from 2 rows and 3 columns to 4 rows and 5 columns, with the same patter. In this pattern, it was captured that the students have tried to be generalized the pattern by developing a bijection.

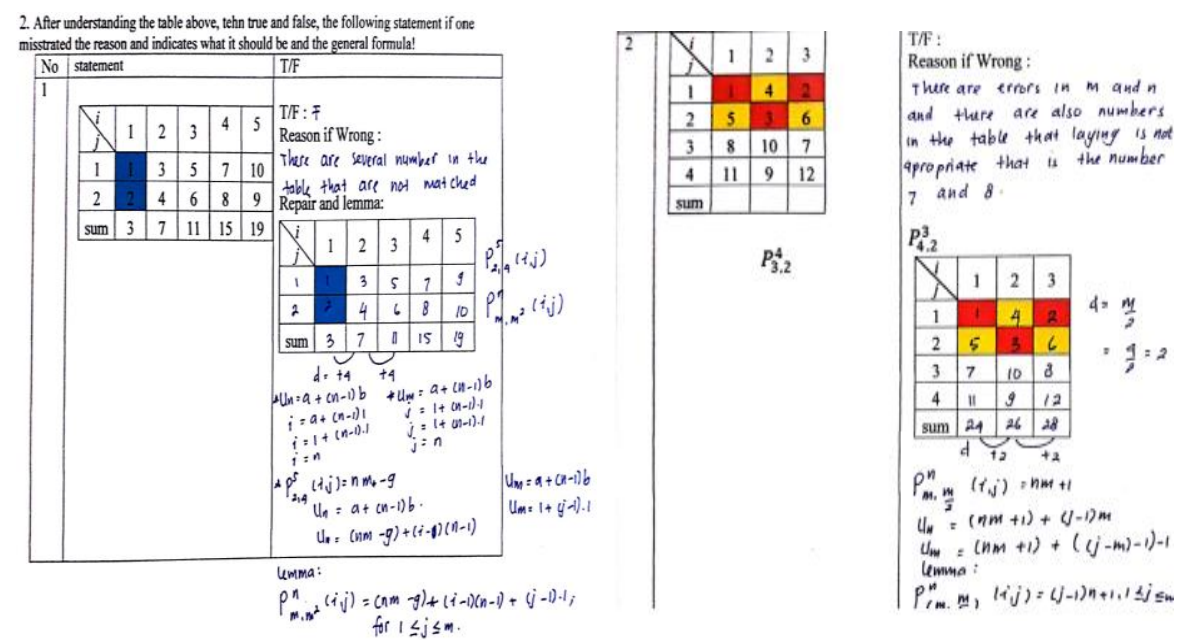

Figure 7

The generalization process of the pattern of $P_{m, m}^{n}(i, j)$ and $\mathrm{f} P_{m, m / 2}^{n}(i, j)$

When we combine the two patterns above, we have the following table. 


\begin{tabular}{|c|c|c|c|}
\hline$j i$ & 1 & 2 & 3 \\
\hline$j$ & & & \\
\hline 1 & 1 & 4 & 2 \\
\hline 2 & 5 & 3 & 6 \\
\hline 3 & 7 & 8 & 9 \\
\hline 4 & 10 & 11 & 12 \\
\hline sum & 17 & 19 & 21 \\
\hline
\end{tabular}

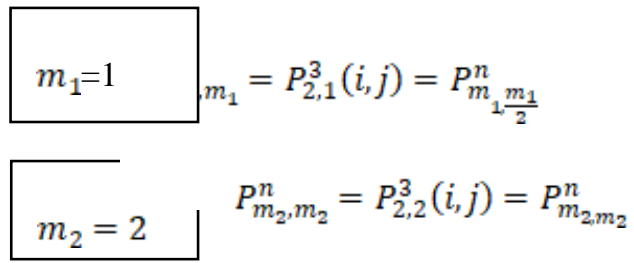

Figure 8

The combination of the two patterns of $P_{m, m}^{n}(i, j)+\mathrm{f} P_{m, m / 2}^{n}(i, j)$

Finally, to know the students' perception about the implementation of Research Based Learning in solving two-dimensional arithmetic sequence problem, the researchers conducted interviews to students. In order to address ethical issues, the researchers made the student's name anonymous, as they were simply represented by "Researcher" and "Student". The data obtained from interviews are discussed below.

Researcher : After reading the item, what have you understood?

Student $\quad$ I realized that the same colors represented a sequence, regardless of the colors.

Researcher : was there any information you gained after answer the question?

Student $\quad$ : Yes, I found that after all areas had been covered, different $d$ was evident. Also, the arrow was followed by a sequence to the right.

Researcher : How did you accomplish the second item?

Student $\quad:$ I had to create simple pattern first and then expanded downwards and to the right.

Researcher : When dealing with the post-test, how did you manage to understand the point?

Student

: Basically, it was just similar to the pre-test. The only difference was that I had to be really careful when identifying whether the item was correct or incorrect and providing the reasons to our judgment.

Researcher : On the post-test, what appeared to be the difficulty?

Student $\quad$ : The difficulty lied in combining different patterns in one table. It was confusing when I need to expand the pattern and find the difference $d$.

Researcher : Once you have a specific pattern of two-dimensional arithmetic

International Journal of Instruction, January2019 • Vol.12, No.1 
sequence, can you generalize it and write a report easily?

Student : The difficulty lied in combining different patterns in one table. It was confusing when I need to expand the pattern and find the difference $d$.

\section{DISCUSSION}

Our research question is to explore the effectiveness of Research Based Learning in improving students' achievement in solving two-dimensional arithmetic sequence problems compared with the conventional learning model. The results show that implementation of RBL results in more effective compared with the conventional learning model. This result is in line with Sutarto's research result stating that generalization process is very important to solve the pattern of numbers (Sutarto, et al, 2018). Sota \& Peltzer report that the application of RBL among master-degree students when dealing with reading, analysing, synthesising, and presentation as well as discussion can improve cognitive skill, knowledge, ethics, competence, social skills, communication, arithmetic and information technology skills, and satisfaction in finding information, which are all found at high extent (Sota 2017). RBL can be fully recommended for engineering education so as to produce higher students' motivation and improve learning outcomes and more well-developed life aspects (Nadine 2015). Alacapina mentioned that the average cognitive outcome of students taught using the RBL-based is found to be significantly higher than that the other group. Based on these findings, it can be asserted that research based learning models are effective in achieving targets in cognitive outcomes (Alacapina 2008). Furthermore, RBL should be applied in many departments to expand research in studies across all institutions, apply research in education, and strengthen the relationship between research and teaching (Schapper \& Mayson, 2010). If RBL is applied in classroom, students will be more active and creative and think more critically than students taught using conventional learning. This is because providing a fun atmosphere for students can foster learning process. This is in line with Marian's research which states that in RBL-based learning the students are encouraged to carry out research themselves. It involves students so that they are no longer passive information receiver, but active knowledge seekers. Innovative classrooms break down the walls of boredom and apathy. They engage and motivate students to take an active part in learning. Students are involved in collaboration, which includes teaching, sharing, and learning process. They thus become knowledge constructors. Students become collaborators to build understanding. New learning goals change the relationship between conventional classroom instruction and assessment in which students tend to be passive and are less encouraged to explore their potential. In conventional class, students tend to be passive and they are less encouraged to explore their potential.

\section{CONCLUSION}

The research result proves that Research Based Learning model is more effective in solving two-dimensional arithmetic sequence problems compared with the conventional learning model. Research Based Learning model also contribute to the class such that 
the class is more active and creative and students think more critically than students taught using conventional learning. This is because providing a fun atmosphere for students can foster learning process becoming much more conducive. However, solving two-dimensional arithmetic sequence problem is a complex problem even that it is considered to be No-diterministics Polynomial (NP) problem. Thus, RBL implementation is less effective in the generalization phase done by students. Therefore, we need to propose the following suggestions for further researcher (1) Research Based Learning model on combinatorics studies should be further developed for other combinatorial problems in addition to assisting the consistency of the effectiveness of RBL. (2) Need to revise the syntax especially when students step up to the generalization process, (3) Determine whether the RBL model can contribute effectively to the students higher order thinking skills in solving combinatorial problems in general.

\section{ACKNOWLEDGMENT}

We gratefully acknowledge the support from Faculty of Teacher Training and Education - the University of Jember, especially Postgraduate Program of Mathematics Education and CGANT - University of Jember of year 2018.

\section{REFERENCES}

Bača, M., Brankovic, L., Lascsakova, M., Phanalasy, O., \& Semaničová-Feňovčíková, A. (2013). On d-Antimagic Labelings of Plane Graphs. Electronic Journal of Graph Theory and Applications, 1(1), 28- 39.

Blackmore, P., \& Fraser, M. (2007). Research Based Learning Strategies for Successfully Linking Teaching and Research. Journal of Education, 13(2), 1-13.

Blume, S., Madanchi, N., Böhme, S., Posselt, G., Thiede, S., \& Herrmann, C. (2015). Die Lernfabrik - Research-based Learning for Sustainable Production Engineering. Procedia CIRP, 32, 126-131.

Brew, A. (2010). Imperatives and Challenges in Integrating Teaching and Research. Higher Education Research \& Development, 29(2), 139-150.

Dafik. (2015). Graph Theory, Applications and The Growth of High-Level Thinking Skills. CGANT Research Group Universitas Jember.

Dafik. (2016). Developing and Research Based Curriculum for Higher Education. Jember: Universitas Jember.

Dafik, Slamin, Tanna, D., Semaničová-Feňovčíková, A., \& Bača, M. (2017). Constructions of H-Antimagic Graphs Using Smaller Edge-Antimagic Graphs. Ars Combinatoria, 133, 233-245.

Hinton, P.R., McMurray, I., \& Brownlow, C. (2004). SPSS Explained. Routledge Inc, New York. 
Hobri, Dafik, \& Hossain, A. (2018). The Implementation of Learning Together in Improving Students' Mathematical Performance. International Journal of Instruction, 11(2), 483-496.

Noormandiri, B.K. (2018). Mathematics for high school class XI program of Natural Sciences. Jakarta: Erlangga.

Pólya, G., Tarjan, R. E., \& Woods, D. R. (2009). Notes on Introductory Combinatorics. Springer Science \& Business Media.

Schapper, J., \& Mayson, S. E. (2010). Research-led Teaching: Moving from a Fractured Engagement to a Marriage of Convenience. Higher Education Research \& Development, 29, 641-651.

Sota, C., \& Karl, P. (2017). The Effectiveness of Research Based Learning among Master degree Student for Health Promotion and Preventable Disease, Faculty of Public Health, Khon Kaen University, Thailand. Procedia-Social and Behavioral Sciences, 237, 1359-1365.

Strauss, A., \& Corbin, J. (2012). The Basics of Qualitative Research: Grounded Theoretical Procedures and Techniques. Newberry Park, CA: Sage.

Sugiyono. (2017). Quantitative, Qualitative, and R \& D Research Methods. Bandung: ALFABETA, Indonesia.

Sutarto, Nusantara, T., Subanji, Hastuti, I. D., \& Dafik. (2018). Global Conjecturing Process in Pattern Generalization Problem. Journal of Physics: Conference Series, $1008(1), 012060$.

Zaenal, A. (2017). Developing The Student Creative Thinking Skill, Critical Thinking Instruments of 21st Century Mathematics Learning. 4(5), 1-9. 